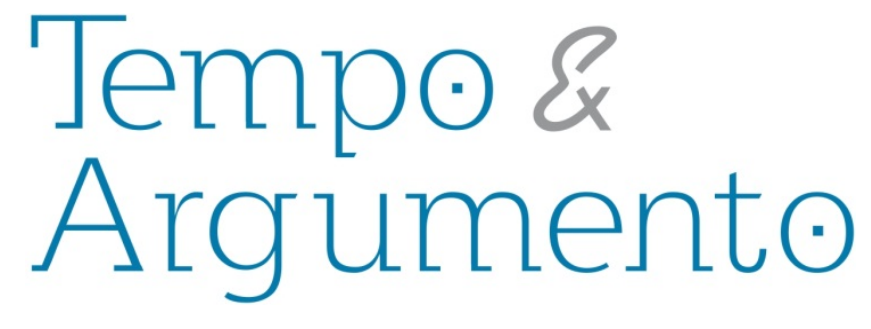

\title{
Biografia e História: da academia ao grande público
}

\section{Resenha da obra:}

DEL PRIORE, Mary. O Castelo de Papel: uma história de Isabel de Bragança, princesa imperial do Brasil, e Gastão de Orléans, conde D’Eu. Rio de Janeiro: Rocco, 2013.

Autora:

\section{Marilane Machado}

Doutoranda em História do Programa de Pós-Graduação em História da Universidade Federal do Paraná (UFPR).

Técnica em Educação da

Universidade do Estado de Santa Catarina (UDESC).

Brasil

marilanemac@ig.com.br

\section{Para citar esta resenha:}

MACHADO, Marilane. Biografia e História: da academia ao grande público. Revista Tempo e Argumento, Florianópolis, v. 7, n.14, p. 253 - 258, jan./abr. 2015. 
A partir dos anos 1980, pôde-se testemunhar uma significativa mudança nas ciências humanas em geral e, particularmente, entre os historiadores: uma redescoberta da biografia, que passou a ser reivindicada pela historiografia enquanto possibilidade de escrita da história (DOSSE, 2009, p. 16). Esta afirmação está ligada à realidade francesa analisada por François Dosse. Podemos verificar que também no Brasil as biografias passaram para o primeiro plano da historiografia do final do século XX (SCHMIDT, 2000, p. 50-51) e que, a partir daí, o gênero não parou de ascender, tendo crescido cerca de 20\% entre 2008 e 2011 no Brasil, conforme relatório divulgado pela Fundação Instituto de Pesquisa Econômica (Fipe), encomendado pela Câmara Brasileira do Livro e pelo Sindicato Nacional de Editores de Livros (BASSO, 2013, p. 26).

Dentro deste contexto de crescimento editorial do gênero biográfico, aliada a uma mudança nas bases teórico-metodológicas da historiografia, encontra-se a última biografia escrita por Mary Del Priore: “O Castelo de Papel: uma história de Isabel de Bragança, princesa imperial do Brasil, e Gastão de Orléans, conde D’Eu”. A obra nos permite reflexões profícuas acerca das contribuições do gênero biográfico enquanto possibilidade de escrita da História, tais como as formas de narrativa e a relação entre indivíduo e sociedade nos escritos biográficos e historiográficos.

Mary Del Priore, renomada historiadora brasileira, é atualmente professora do Programa de Mestrado em História da Universidade Salgado de Oliveira - Universo/Niterói. É conhecida, no meio acadêmico, por seus estudos nas áreas de História do Brasil Colonial - da qual também foi professora na Universidade de São Paulo -, de história das mulheres, da criança, do corpo e da sexualidade, e vem se destacando nos últimos anos por suas obras direcionadas ao grande público, além da produção de biografias, sobretudo ligadas a membros da família imperial brasileira no decorrer do século XIX.

O livro está dividido em 11 capítulos e compreende um período de 25 anos da vida do casal biografado: entre 1864, ano do casamento, e 1889, ano da Proclamação da República, quando a família imperial teve que se retirar do Brasil. Trata-se de uma biografia entrelaçada da Princesa Isabel e do Conde D’Eu, na qual é possível visualizar um personagem através do olhar do outro. 
Nos dois capítulos iniciais, a autora lança mão do recurso narrativo de flashback. Muito utilizado na literatura e no cinema, a historiadora se apropria do recurso para apresentar aos leitores os dois personagens centrais da obra antes do casamento. Ele, membro da família Orléans, era filho do conde de Nemours e neto de Maria Amélia, rainha dos franceses, à época exilada na Inglaterra. Ela, princesa do Brasil e futura imperatriz, sucessora de Dom Pedro II ao trono.

No capítulo final, dedicado ao que Isabel nomeou de o dia da "maior infelicidade de nossa vida", o 15 de novembro de 1889, a autora retrata como os acontecimentos daquela data foram vistos pelos membros da família imperial e pela opinião pública e traça um breve panorama da vida familiar no exílio, até a morte dos imperadores, Isabel e Gastão. A autora dedica 16 páginas do capítulo final aos 30 anos da vida do casal no exílio, o que demonstra sua escolha em retratar a vida num momento histórico específico: a decadência do Império brasileiro e a clareza de que o biógrafo não é obrigado a se dedicar à totalidade da vida do biografado, senão aos aspectos que a documentação permite compreender.

Utiliza fontes privilegiadas para a escrita da obra: documentos do Arquivo Histórico do Museu Imperial de Petrópolis; Archives Génerales du Royaume et Archives de L'Etat dans les Provinces - Bruxelas/Bélgica; Instituto Histórico e Geográfico Brasileiro; Biblioteca Nacional. Grande parte da documentação era composta de correspondências da família Orléans, documentos inéditos que permitiram visualizar a dimensão privada da vida do casal, sua relação íntima, seu cotidiano, e a figura humana, através das cartas enviadas aos familiares, aos amigos e as trocadas entre si, que mostram como esta se sobrepõe à figura política.

A autora não se limita, no entanto, à vida privada dos biografados. Como figuras públicas que foram, a dimensão política e o contexto da crise do sistema imperial no Brasil e no mundo são abordados no livro, a partir da documentação consultada, sobretudo os periódicos: A Semana llustrada; Jornal do Commercio; A Vida Fluminense; A Reforma; A República; Diário do Rio de Janeiro; O Mequetrefe; O Protesto; Jornal de Três; Cidade do Rio; Diário de Notícias; Gazeta da Tarde; Gazeta de Notícias e O Corsário. Além disso, ao final da obra, fornece uma vasta referência bibliográfica. Assim, a biografia permite ir além da apresentação da vida pessoal das personagens e, através delas, acessar o contexto histórico que envolve 
suas vidas, mais especificamente a crise do Império e a ascensão do regime republicano no Brasil.

A pluralidade de fontes acessadas pela historiadora e, sobretudo, o acesso às inéditas correspondências arquivadas em Bruxelas permitiram a Mary Del Priore traçar um perfil de Isabel, que vai além de sua conhecida atuação política. É possível visualizar a personagem como mãe, esposa, mulher apaixonada, apesar do casamento contratual que servia politicamente para unir famílias nobres. Parte desta abordagem íntima para o papel de futura herdeira da coroa imperial. Neste âmbito, Mary Del Priore traça o perfil de uma personagem ainda desconhecida na historiografia.

A Isabel que ela revela não é a Isabel da articulação política, que assinou a lei de 13 de maio de 1888 numa atitude calculada. Também não é a "redentora", como a chamou pela primeira vez José do Patrocínio, ao atribuir à sua bondade a libertação dos cativos no Brasil. Através das fontes, a autora apresenta uma Isabel alheia às questões políticas e muito mais envolvida com o contexto familiar.

Embora tenha sido preparada desde a adolescência para suceder a Dom Pedro II, com horas dobradas de estudo em relação a outras moças, e tendo acesso a conhecimentos não destinados às mulheres no período, a autora demonstra, em várias passagens, a inaptidão e a falta de interesse da princesa para assuntos de Estado e sua franca preferência pela vida de mulher de acordo com o estereótipo feminino do século XIX: obediente ao pai, depois ao marido, sensível e religiosa.

A autora mostra que, embora Isabel se interessasse pela causa abolicionista, este interesse aflorou tarde, somente poucos meses antes da assinatura da Lei Áurea; mesmo assim, suas ações eram qualificadas, sobretudo pelos mais radicais da época, como futilidades. Giravam geralmente em torno de festas, concertos e batalhas de flores, ações consideradas pouco expressivas e muito ligadas a um sentimento religioso católico, apiedando-se dos cativos, mas negando-lhes qualquer possibilidade de articulação em torno das lutas que travavam pela própria liberdade.

Gastão de Orléans, o Conde D’Eu, também é apresentado como o modelo esperado de um homem do século XIX: que assume a liderança da casa, da vida do casal e que serviria de 
principal conselheiro político à futura imperatriz. A partir da análise de correspondências de Gastão, sobretudo das que trocava com seu pai e com a condessa de Barral, emerge, na narrativa da historiadora, uma personagem que demonstrava, dentre todos os apresentados, a visão política mais sensata daquele momento histórico.

Dom Pedro, personagem secundária, mas muito presente na narrativa, é apresentado, na percepção de Gastão em suas correspondências, como uma figura "cinzenta", que afastou o casal de príncipes da vida política e a quem faltou habilidade política em várias situações apresentadas no texto. Afastados pelo imperador dos deveres públicos, o casal parece ter encontrado sentido maior na vida a dois, procurando envolver-se o mínimo necessário com as questões de Estado. Mary Del Priore conseguiu captar e transmitir ao público leitor esses aspectos da intimidade do casal, sobretudo pela qualidade das fontes consultadas, que privilegiaram tal abordagem.

É nítido que a narrativa final é fruto de extensa pesquisa documental e bibliográfica e da crítica a fontes primárias, condição sine qua non para a escrita historiográfica. No entanto, não se trata de uma obra direcionada estritamente ao público acadêmico, mas que visa a atingir um público mais amplo. O pesquisador atento poderá encontrar na narrativa de Mary Del Priore as fontes e as referências bibliográficas, embora não as cite em notas de rodapé, limitando-se a incorporar partes do texto dos documentos à sua narrativa entre aspas e a citálos em listas ao final do livro. O leitor que não faz parte da academia ou das lides historiográficas poderá ter um contato íntimo com personagens caras à história do Brasil imperial e reconhecer-se em muitas atitudes, sentimentos e anseios das personagens, além de ter acesso a temas importantes de nossa história política. Poderá deliciar-se com uma narrativa leve, encantadora e fazer uma espécie de viagem no tempo até o século XIX, compreendendo parte daquele contexto. Por fim, pode-se afirmar do livro que se trata de um primoroso exemplar de como a história pode, através de um texto biográfico, transpor os limites do universo acadêmico e atingir o grande público. 


\section{Referências}

DOSSE, François. O Desafio Biográfico: Escrever uma Vida. São Paulo: Editora da Universidade de São Paulo, 2009.

SCHMIDT, Benito Bisso. Luz e papel, realidade e imaginação: as biografias na história, no jornalismo, na literatura e no cinema. In: SCHMIDT, Benito Bisso (Org.). O biográfico: perspectivas interdisciplinares. Santa Cruz do Sul: EDUNISC, 2000.

BASSO, Murilo. O gênero (quase) fora da lei. In: Cândido: Jornal da biblioteca pública do Paraná, Curitiba, n. 23, jun. 2013, p. 26-29. 